\title{
Review of Factors Contributing to Nodular Goiter and Thyroid Carcinoma
}

\author{
Ilgin Yildirim Simsir Sevki Cetinkalp Taylan Kabalak \\ Division of Endocrinology and Metabolism Disorders, Department of Internal Medicine, Ege University Medical \\ Faculty, Izmir, Turkey
}

\section{Significance of the Study}

- In recent years, there has been an increased incidence of thyroid nodules and thyroid cancer.

- Metabolic syndrome and insulin resistance are among the important factors causing the increased incidence of nodular goiter and thyroid cancer today.

\section{Keywords}

Nodular goiter · Thyroid cancer

\section{Abstract}

There is an increased incidence of thyroid nodules and cancer. In this article, the reasons for this increase are evaluated and discussed. The factors causing increases in the incidence of nodules are the same as those causing increases in thyroid cancer. There are publications from all over the world regarding the rising incidence of thyroid cancer; it is especially associated with papillary cancer. The literature was reviewed and evaluated with regard to this significant phenomenon. Thyroid-stimulating hormone (TSH) is the main mitotic factor. Any agent that elevates TSH will stimulate nodule formation. Therefore, the incidence of thyroid nodules is high in endemic goiter regions due to iodine deficiency. This paper has described many of the factors causing this higher incidence. Of note, metabolic syndrome and insulin resistance are important factors associated with the increased incidence of nodular goiter and papillary thyroid cancer today. However, these data must be confirmed by other studies in the future.

(c) 2019 The Author(s)

Published by S. Karger AG, Basel

\section{KARGER}

E-Mail karger@karger.com www.karger.com/mpp

\section{(C) 2019 The Author(s)}

Published by S. Karger AG, Basel

Karger

Open access

This is an Open Access article licensed under the Creative Commons Attribution-NonCommercial-4.0 International License (CC BY-NC) (http://www.karger.com/Services/OpenAccessLicense), applicable to the online version of the article only. Usage and distribution for commercial purposes requires written permission.

\section{Introduction}

Normal thyroid follicles (thyrocytes) are formed from single-row epithelial cells. One thyrocyte may have a robust ability in hormone synthesis and secretion, while another in the same follicle may display very low levels of hormone synthesis and secretion. In the same follicle, one thyrocyte may have excessive iodine retention, whereas it may be very low in another. In addition, while a thyrocyte may show an excessive mitotic response to proliferative stimuli, a neighboring thyrocyte in the same follicle may have very low mitotic characteristics [1]. Thus, there is considerable heterogeneity between thyrocytes in the same follicle.

These variations cause differences in the hyperplastic nodules originating from these cells. If there is high sodium/iodine symporter activity in a thyrocyte with an excessive response to mitotic stimulation, a nodule originating from this will be characterized scintigraphically as a normoactive or hyperactive nodule. On the other hand, if mitotic activity is low in a nodule with high sodium/ iodine symporter activity, the resulting nodule will be a scintigraphically cold nodule due to low iodine retention, and will display different echogenicity via ultrasound. 
Thyroid-stimulating hormone (TSH) is the main mitotic factor. Iodine deficiency is the leading cause of increases in TSH. Thus, the incidence of nodules is high in regions with endemic goiter due to iodine deficiency. Selenium deficiency also causes goiter and nodular goiter, albeit via a different pathway. Some chemicals (e.g., nitrate and perchlorate) can cause goiter by affecting iodine uptake or hormone synthesis.

Physical examination is important for the diagnosis of thyroid nodules. Nodules $1 \mathrm{~cm}$ in size or greater can be detected by careful thyroid palpation only if they are situated in an anterior location. This examination can determine the location, rough dimensions, and consistency of a nodule. The likelihood that the thyroid nodule is cancerous increases in the presence of pathologic lymphadenopathy. The nodule detection rate by palpation decreases for individuals with short necks and obese people. Furthermore, it is not possible to detect nodules located in the back of the thyroid.

Ultrasound is the most common initial radiological approach used to detect and characterize thyroid nodules [2-4]. Thyroid nodules may be incidentally detected on examination by computed tomography (CT), magnetic resonance imaging, and positron emission tomography. Scintigraphy is not a routine laboratory method for evaluating nodules. However, if TSH is at the lower limit or is suppressed further in an individual with nodular goiter, scintigraphy is used to assess whether the nodule is functioning autonomously.

There is an increased incidence of thyroid nodules despite the use of iodine prophylaxis in many countries [2]. One of the leading causes of nodule detection is the increased use and sensitivity of radiological imaging. Ultrasound can currently detect nodules as small as $1-2 \mathrm{~mm}$, causing the incidence of nodules to increase to 60,000 70,000 per 100,000 adults in a population. This number was below 10,000 when palpation and scintigraphy were the only methods used for nodule evaluation. However, it is unlikely that the increase in nodules is only associated with the development of improved radiological imaging. Many studies have found that the incidence of nodular goiter is increased even when this factor is eliminated. The cancer rate of nodular goiter is around $5 \%$. The rate does not differ between single nodules and multinodular goiter [2,3].

The factors contributing to increases in nodules are the same as those contributing to increases in thyroid cancer. These increases are especially associated with papillary thyroid cancer, and partially associated with the use of ultrasound and fine-needle aspiration biopsy.
However, when these factors are statistically eliminated, there is still a clear increase in papillary thyroid cancer.

Thus, the causes of the increased incidence of thyroid nodules and thyroid cancer are still not understood.

\section{Radiation}

Radiation directed at the thyroid in individuals under the age of 20 years increases the incidence of nodular goiter in early years, and then increases the incidence of papillary cancer in later years. Thyroid irradiation may be caused by radiography performed at young ages on CT examinations and administration of radioactive iodine. The increasing overuse of imaging in medicine is one of the important factors believed to affect the growing epidemic of thyroid nodules and papillary thyroid cancer [5].

The most striking example of radiation exposure is the accident at the Chernobyl nuclear reactor in 1986. The incidence of nodular goiter increased among children and adolescents during the first 2-4 years after the accident, while that of papillary cancer increased after 4 years $[2,4]$. Chernobyl was the first example of ingested and inhaled radioiodine resulting in radiation-induced thyroid tumorigenesis.

\section{lodine}

Several studies have shown that rates of goiter, nodular goiter, and papillary thyroid cancer are higher in iodineinsufficient areas than in those that have sufficient iodine $[6,7]$. Iodine deficiency has been shown to lead to these conditions by increasing TSH levels. However, when goiter prophylaxis is performed with high doses of iodine in iodine-insufficient areas, it can sometimes cause iodine excess, which also causes an increase in papillary thyroid cancer. Areas with primary iodine excess, such as Japan and Hawaii, have been shown to have a high incidence of papillary thyroid cancer [2].

\section{Environment}

Today's environment exposes the public to many harmful chemicals. These chemicals can come from the water, air, or food, including many ready-made food products. The public is most commonly exposed to nitrates. As nitrates are used for many agricultural purposes, they may leach into drinking water, exposing the pub- 
lic to nitrates. Nitrates can also be found in industrial nutritional products. In addition, the public is also exposed to chemicals such as benzene, formaldehyde, pesticides, bisphenol A, polychlorinated biphenyl, polyhalogenated aromatic hydrocarbons, and polybrominated diphenyl ether. These chemicals have been shown to cause goiter and nodular goiter, and some may also cause papillary thyroid cancer due to their genetic properties [2].

\section{Mutations}

Many mutations can lead to nodular goiter and papillary thyroid cancer. About $4-6 \%$ of patients with nodular goiter have a $R A S$ mutation, and about $74-87 \%$ of those with a $R A S$ mutation have benign or malignant neoplasia. The RAS mutation has a positive predictive value of $78 \%$ and a negative predictive value of $64 \%$. Mutations in $P A X 8 / P P A R \gamma, R E T / P T C, B R A F$, and RAS have been reported in papillary thyroid cancer, which is the most common thyroid cancer. BRAF and TERT promoter mutations have also been reported to cause clinical differences in thyroid-differentiated cancers. Mitotic cycleweighted mutations have been also mentioned in more aggressive papillary thyroid cancer types. Mutations in SPOP (4/38), ZNF148 (6/38), and EZH1 (3/38) have been reported in benign nodules. However, despite differences in various studies, the mutation detection rate in nodular goiter is less than $10 \%$ [8-10].

\section{Insulin Resistance, Metabolic Syndrome, and Their Association with Thyroid Nodule}

Some of the most important causes of goiter, nodular goiter, and papillary thyroid cancer are metabolic syndrome and insulin resistance. Several recent studies have focused on the relationships between metabolic syndrome, thyroid growth in insulin resistance, increases in the thyroid nodule rate, and increases in the papillary thyroid cancer rate [11-20]. The Homeostasis Model Assessment of Insulin Resistance (HOMA-IR) has been shown to be positively associated with thyroid volume and the presence of a nodule [9]. Indeed, there is a positive relationship between all of the components of metabolic syndrome and the frequency of nodular goiter. However, the closest association is that of insulin resistance with thyroid nodule and papillary thyroid cancer.

The same association is seen in obesity, albeit independently of insulin resistance. A hazard ratio of 1.53 has been reported in terms of papillary thyroid cancer in obese males and females (BMI $\geq 30 \mathrm{~kg} / \mathrm{m}^{2}$ ). A meta-analysis of 21 studies revealed that the incidence of papillary cancer increases while that of medullary cancer decreases among obese individuals. Another meta-analysis showed that an increase of $5 \mathrm{~kg} / \mathrm{m}^{2}$ in BMI is associated with a significant increase in papillary thyroid cancer risk (relative risk $=1.33$ ) [21]. Obesity has been shown to promote the progression of thyroid cancer. The molecular mechanisms by which obesity increases thyroid cancer risk and facilitates cancer progression are not completely understood [22].

Below, we discuss the different pathways regarding the pathogenesis of metabolic syndrome-insulin resistance with thyroid hyperplasia, thyroid nodule, and cancer. Chronic inflammation in obesity, metabolic syndrome, and insulin resistance is a risk factor for many types of cancer. In obesity, the release of proinflammatory factors from adipose tissue increases, while the release of adipokines decreases. Proinflammatory factors act as signal mediators of peritumoral tissue in tumor growth and progression. As the adipose tissue increases, leptin synthesis increases, and the chronic inflammation in enlarged adipose tissue augments the secretion of the cytokines IL-6 and TNF, which contribute to cancer development, growth, progression, and metastasis [23]. Aberrant expression of leptin and/or its receptor has been found in a variety of malignancies including thyroid carcinoma $[24,25]$. In vitro studies have shown that leptin modulates the growth, proliferation, and invasion of thyroid carcinoma cell lines via activation of various signaling pathways such as Janus kinase/signal transducer and activator of transcription, phosphoinositide 3-kinase/protein kinase $\mathrm{B} / \mathrm{Akt}$, and/or mitogen-activated protein kinase (MAPK) [24, 25].

\section{Thyroid-Stimulating Hormone}

TSH is a predominantly proliferative molecule for the thyroid. Elevation of serum levels of TSH causes significant increases in thyroid volume. Elevations, even minimal elevations, in TSH over an adequate amount of time are sufficient for goiter formation. Iodine-insufficient endemic goiter areas have many examples of this pathogenesis. It has been shown that mild or moderate elevations in TSH are generally detected in these areas and are among the main reasons for goiter formation.

Obese individuals often have increased leptin in the circulation, which reduces the formation of triiodothyro- 
nine by suppressing the effect of type II deiodinase on the paraventricular nucleus TRH neurons in the hypothalamus. This increase in TRH stimulates the secretion of TSH in the hypophysis. The mean TSH level in obese individuals is $0.8-2.0 \mathrm{mU} / \mathrm{L}$ higher than that in nonobese individuals. Over time, this slight elevation can cause an increase in the incidence of goiter, nodular goiter, and papillary thyroid cancer $[26,27]$.

\section{Association between Hyperinsulinemia, Insulin Receptor, Insulin-Like Growth Factor, and Thyroid Nodule/Cancer}

Hyperinsulinemia refers to chronic insulin excess and reveals the mitogenic effect of insulin. This effect induces tissue hyperplasia by stimulating cell division and prolongs cell survival by inducing antiapoptotic effects [11]. Insulin receptor levels have been shown to be increased in thyroid cancers $[28,29]$. The insulin receptor and the insulin-like growth factor (IGF) receptor (IGFR) are structurally homologous. Thus, insulin can bind to both the insulin receptor and the IGFR. Further, an insulin receptor and an IGFR can dimerize to form a hybrid receptor, leading to inappropriate binding [11]. When insulin binds to its receptor, the phosphoinositide 3-kinase pathway is activated, leading to glucose uptake. In addition, the MAPK cascade is also activated with insulin binding. The MAPK pathway is responsible for cell and tissue proliferation as well as for gene expression. Normally, the MAPK pathway is upstream of glucose uptake, but the MAPK pathway is limited at the physiological level. However, the MAPK pathway also plays a major role in chronic hyperinsulinemia in insulin resistance [11].

Activation of IGFR is also very important in insulin resistance. IGFR activation is thought to play a major role in many types of cancer, with an increased incidence in metabolic syndrome. It also plays a role in thyroid cancer. In cases of insulin resistance, the amount of circulating IGF-binding proteins that bind IGFs is reduced. As a result, circulating free IGFs are increased, and, therefore, IGFs that are naturally associated with IGFRs will increase. The mitogenic effect of the IGFR signal chain is also known to play a role [28-30].

IGFRs do not occur very densely in the normal thyrocyte membrane. However, IGFR membrane densities are significantly increased in thyroid nodules and cancers. IGFRs have been scintigraphically found to occur more densely in cell membranes of cold (noncancerous) nodules than in normoactive and, especially, hyperactive nodules [28-30]. Insulin resistance stimulates the IGF pathway as well as the insulin pathway in thyroid tissue.

Increased levels of insulin receptor expression have been observed in differentiated and undifferentiated thyroid cancer tissues. The addition of metformin to the environment inhibits the increase in tumor cells [31]. This inhibition has been associated with activation of adenosine monophosphate kinase in cell pathways, as well as with the subsequent inhibition of the mammalian target of rapamycin pathway [31]. In a retrospective cohort study evaluating Korean national health data, 128,453 individuals who used metformin and 128,453 who did not use metformin were evaluated for papillary thyroid cancer over a 7.8-year follow-up period. The results of that study revealed that metformin has a protective effect against the development of thyroid cancer. However, depending on the cumulative dose of metformin, this beneficial effect emerges in later, but not in early, periods. This beneficial effect is particularly pronounced in diabetic individuals, especially in the age range of 50-64 years [32]. Another study revealed that metformin led to a high remission rate and lower recurrence of cervical lymph node metastasis [33]. However, these data must be confirmed by other studies in the future.

\section{Conclusions}

Obesity, an increasing pandemic in the world, is defined as an abnormal or excessive amount of fat accumulation to the extent that it impairs human health. According to the 2014 report of the World Health Organization, more than 1.9 billion adults are overweight (39\%) and over 600 million adults are obese (13\%) [34]. In recent years, there has been an increased incidence of thyroid nodules and thyroid cancer. Many of the factors causing this higher incidence have been discussed here. Of note, obesity, metabolic syndrome, and insulin resistance may be the most important factors causing the increased incidence of nodular goiter and thyroid cancer today.

\section{Disclosure Statement}

The authors declare no potential conflicts of interest.

\section{Funding Sources}

No funding was received for this review. 


\section{References}

1 Studer H, Peter HJ, Gerber H. Natural heterogeneity of thyroid cells: the basis for understanding thyroid function and nodular goiter growth. Endocr Rev. 1989 May;10(2):125-35.

2 Pellegriti G, Frasca F, Regalbuto C, Squatrito $S$, Vigneri R. Worldwide increasing incidence of thyroid cancer: update on epidemiology and risk factors. J Cancer Epidemiol. 2013; 2013:965212.

3 Jiang H, Tian Y, Yan W, Kong Y, Wang H, Wang A, et al. The Prevalence of Thyroid Nodules and an Analysis of Related Lifestyle Factors in Beijing Communities. Int J Environ Res Public Health. 2016 Apr;13(4):442.

4 Popoveniuc G, Jonklaas J. Thyroid nodules. Med Clin North Am. 2012 Mar;96(2):329-49.

5 Iglesias ML, Schmidt A, Ghuzlan AA, Lacroix L, Vathaire F, Chevillard S, et al. Radiation exposure and thyroid cancer: a review. Arch Endocrinol Metab. 2017 Mar-Apr;61(2):180-7.

6 Cao LZ, Peng XD, Xie JP, Yang FH, Wen HL, Li S. The relationship between iodine intake and the risk of thyroid cancer: a meta-analysis. Medicine (Baltimore). 2017 May; 96(20):e6734.

7 Zimmermann MB, Galetti V. Iodine intake as a risk factor for thyroid cancer: a comprehensive review of animal and human studies. Thyroid Res. 2015 Jun;8:8.

8 Radkay LA, Chiosea SI, Seethala RR, Hodak SP, LeBeau SO, Yip L, et al. Thyroid nodules with KRAS mutations are different from nodules with NRAS and HRAS mutations with regard to cytopathologic and histopathologic outcome characteristics. Cancer Cytopathol. 2014 Dec;122(12):873-82.

9 Clinkscales W, Ong A, Nguyen S, Harruff EE, Gillespie MB. Diagnostic Value of RAS Mutations in Indeterminate Thyroid Nodules. Otolaryngol Head Neck Surg. 2017 Mar; 156(3):472-9.

10 Ye L, Zhou X, Huang F, Wang W, Qi Y, Xu H, et al. The genetic landscape of benign thyroid nodules revealed by whole exome and transcriptome sequencing. Nat Commun. 2017 Jun; 8:15533.

11 Tsatsoulis A. The role of insulin resistance/ hyperinsulinism on the rising trend of thyroid and adrenal nodular disease in the current environment. J Clin Med. 2018 Feb;7(3):E37.

12 Răcătăianu N, Leach N, Bondor CI, Mârza S, Moga D, Valea A, et al. Thyroid disorders in obese patients. Does insulin resistance make a difference? Arch Endocrinol Metab. 2017 Dec;61(6):575-83.
13 Tang Y, Yan T, Wang G, Chen Y, Zhu Y, Jiang $\mathrm{Z}$, et al. Correlation between Insulin Resistance and Thyroid Nodule in Type 2 Diabetes Mellitus. Int J Endocrinol. 2017;2017: 1617458.

14 Kir S, Aydin Y, Coskun H. Relationship between metabolic syndrome and nodular thyroid diseases. Scand J Clin Lab Invest. 2018 Feb - Apr;78(1-2):6-10.

15 Buscemi S, Massenti FM, Vasto S, Galvano F, Buscemi C, Corleo D, et al. Association of obesity and diabetes with thyroid nodules. Endocrine. 2018 May;60(2):339-47.

16 Feng S, Zhang Z, Xu S, Mao X, Feng Y, Zhu Y, et al. The Prevalence of Thyroid Nodules and Their Association with Metabolic Syndrome Risk Factors in a Moderate Iodine Intake Area. Metab Syndr Relat Disord. 2017 Mar; 15(2):93-7.

17 Blanc E, Ponce C, Brodschi D, Nepote A, Barreto A, Schnitman M, et al. Association between worse metabolic control and increased thyroid volume and nodular disease in elderly adults with metabolic syndrome. Metab Syndr Relat Disord. 2015 Jun;13(5):221-6.

18 Duran AO, Anil C, Gursoy A, Nar A, Inanc $\mathrm{M}$, Bozkurt $\mathrm{O}$, et al. Thyroid volume in patients with glucose metabolism disorders. Arq Bras Endocrinol Metabol. 2014 Nov;58(8): 824-7.

19 Wang K, Yang Y, Wu Y, Chen J, Zhang D, Mao X, et al. The association between insulin resistance and vascularization of thyroid nodules. J Clin Endocrinol Metab. 2015 Jan; 100(1):184-92.

20 Rezzonico J, Rezzonico M, Pusiol E, Pitoia F, Niepomniszcze H. Introducing the thyroid gland as another victim of the insulin resistance syndrome. Thyroid. 2008 Apr;18(4): 461-4.

21 Liu Y, Su L, Xiao H. Review of Factors Related to the Thyroid Cancer Epidemic. Int J Endocrinol. 2017;2017:5308635.

22 Kim WG, Cheng SY. Mechanisms Linking Obesity and Thyroid Cancer Development and Progression in Mouse Models. Horm Cancer. 2018 Apr;9(2):108-16.

23 Raucci R, Rusolo F, Sharma A, Colonna G, Castello G, Costantini S. Functional and structural features of adipokine family. Cytokine. 2013 Jan;61(1):1-14.
24 Cheng SP, Yin PH, Chang YC, Lee CH, Huang SY, Chi CW. Differential roles of leptin in regulating cell migration in thyroid cancer cells. Oncol Rep. 2010 Jun;23(6):1721-7.

25 Uddin S, Hussain AR, Siraj AK, Khan OS, Bavi PP, Al-Kuraya KS. Role of leptin and its receptors in the pathogenesis of thyroid cancer. Int J Clin Exp Pathol. 2011;4(7):637-43.

26 Ortiga-Carvalho TM, Oliveira KJ, Soares BA, Pazos-Moura CC. The role of leptin in the regulation of TSH secretion in the fed state: in vivo and in vitro studies. J Endocrinol. 2002 Jul;174(1):121-5.

27 Santini F, Marzullo P, Rotondi M, Ceccarini G, Pagano L, Ippolito S, et al. Mechanisms in endocrinology: the crosstalk between thyroid gland and adipose tissue: signal integration in health and disease. Eur J Endocrinol. 2014 Oct;171(4):R137-52.

28 Vella V, Sciacca L, Pandini G, Mineo R, Squatrito $S$, Vigneri R, et al. The IGF system in thyroid cancer: new concepts. Mol Pathol. 2001 Jun;54(3):121-4.

29 Frittitta L, Sciacca L, Catalfamo R, Ippolito A, Gangemi P, Pezzino V, et al. Functional insulin receptors are overexpressed in thyroid tumors: is this an early event in thyroid tumorigenesis? Cancer. 1999 Jan;85(2):492-8.

30 Vannelli GB, Barni T, Modigliani U, Paulin I, Serio M, Maggi M, et al. Insulin-like growth factor-I receptors in nonfunctioning thyroid nodules. J Clin Endocrinol Metab. 1990 Nov; 71(5):1175-82.

31 Kheder S, Sisley K, Hadad S, Balasubramanian SP. Effects of prolonged exposure to low dose metformin in thyroid cancer cell lines. J Cancer. 2017 Apr;8(6):1053-61.

32 Cho YY, Kang MJ, Kim SK, Jung JH, Hahm JR, Kim TH, et al. Protective effect of metformin against thyroid cancer development: a population-based study in Korea. Thyroid. 2018 Jul;28(7):864-70.

33 Klubo-Gwiezdzinska J, Costello J Jr, Patel A, Bauer A, Jensen K, Mete M, et al. Treatment with metformin is associated with higher remission rate in diabetic patients with thyroid cancer. J Clin Endocrinol Metab. 2013 Aug. 98(8):3269-79.

34 World Health Organisation. Obesity and overweight [Internet]. Geneva: WHO Media Centre; 2015. Available from: http://who.int/ mediacentre/factsheets/fs $311 /$ en. 